Review Article

\title{
Nanotechnology- future prospect in recent medicine: a review
}

\author{
Monalisa Jena $^{1}{ }^{*}$, Swati Mishra ${ }^{1}$, Swetalina Jena ${ }^{2}$, Sudhanshu S. Mishra ${ }^{1}$
}

\begin{abstract}
${ }^{1}$ Department of Pharmacology, IMS \& SUM Hospital, Bhubaneswar, India ${ }^{2}$ Department of Microbiology, S.C.B. Medical College, Cuttack, India
\end{abstract}

Received: 9 May 2013

Accepted: 20 May 2013

*Correspondence to:

Dr. Monalisa Jena,

Email: drmonalisajena@gmail.com

(C) 2013 Jena $\mathrm{M}$ et al. This is an openaccess article distributed under the terms of the Creative Commons Attribution License, which permits unrestricted use, distribution, and reproduction in any medium, provided the original work is properly cited.

\begin{abstract}
Any damage at molecular or cellular level is the major culprit for disease \& ill health. Nanotechnology, "the manufacturing technology of the $21 \mathrm{st}$ century," helps us economically build a broad range of complex molecular machines by manipulating matter on an atomic and molecular scale. Nanotech may be able to create many new materials and devices with at least one dimension sized from 1 to 100 nanometres with a vast range of applications, such as in medicine, electronics, biomaterials and energy production. Lots of new possibilities come into account in relation to use of nanotechnology in medicines. Nanotechnology in medicine involves applications of nanoparticles, also involves nano-robots to make repairs at the cellular levels. On the other hand, nanotechnology raises many of the same issues as any new technology, including concerns about the toxicity and environmental impact of nanomaterials.
\end{abstract}

Keywords: Nanotech, Nano robots, Nanoparticles, Nanometers

\section{INTRODUCTION}

Nanotechnology, the manipulation of matter at the atomic and molecular scale to create materials with remarkably varied and new properties, is a rapidly expanding area of research with huge potential in many sectors, ranging from healthcare to construction and electronics. In medicine, it promises to revolutionize drug delivery, gene therapy, diagnostics, and many areas of research, development and clinical application. ${ }^{1}$

The word 'Nano' comes from Greek word means dwarf. In science, nano refers to one billionth $\left(10^{-9}\right)$ of something like nanometer $(\mathrm{nm})$. A nanometer is about 35 atoms wide or 40,000 times smaller than the thickness of human hair. A virus is typically $100 \mathrm{~nm}$ in size.

\section{BRIEF IDEA ABOUT NANOPARTICLES}

Nanoparticles are of great scientific interest as they are an effective bridge between bulk materials \& atomic or molecular structures. The interesting properties of nanoparticles are largely due to large surface area of the material, which dominates the contribution made by the small bulk of materials. However, size is just one of many characteristics of nanoparticles that itself is rarely sufficient if one is to use nanoparticles as biological tags. In order to interact with biological target, a biological or molecular coating or layer acting as a bioinorganic interface should be attached to the nanoparticle. Examples of biological coatings may include antibodies, biopolymers like collagen, ${ }^{2}$ or monolayers of small molecules that make the nanoparticles biocompatible. ${ }^{3}$ In addition, as optical detection techniques are wide spread in biological research, nanoparticles should either fluoresce or change their optical properties.

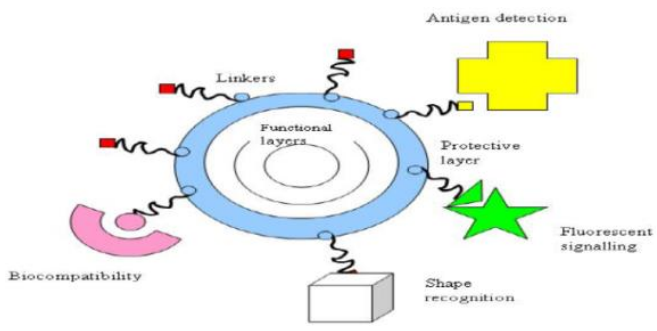

Figure 1: Schematic presentation of approaches used in constructing nano-biomaterials. 
Nano-particle usually forms the core of nano-biomaterial. It can be used as a convenient surface for molecular assembly, and may be composed of inorganic or polymeric materials. It can also be in the form of nanovesicle surrounded by a membrane or a layer. The shape is more often spherical but cylindrical, plate-like and other shapes are possible.

The core particle is often protected by several monolayers of inert material, for example silica. The same layer might act as a biocompatible material. However, more often an additional layer of linker molecules is required to proceed with further functionalisation. This linear linker molecule has reactive groups at both ends. One group is aimed at attaching the linker to the nanoparticle surface and the other is used to bind various moieties like biocompatibles (dextran), antibodies, fluorophores etc., depending on the function required by the application.

\section{Benefits of using nanomaterials:}

a. Smaller devices are less invasive.

b. They can be implanted inside body.

c. Biochemical reaction time is much shorter.

d. Devices are faster \& more sensitive than typical drug delivery. ${ }^{4}$

\section{USES OF NANOMATERIALS IN MEDICINE}

Two forms of nanomedicine that have already been tested in mice and are awaiting human trials are using gold nanoshells to help diagnose and treat cancer, and using liposomes as vaccine adjuvants and as vehicles for drug transport. ${ }^{5,6}$ Similarly, drug detoxification is also another application for nanomedicine which has shown promising results in rats. ${ }^{7}$

\section{A. Drug Delivery System}

The whole system leads to a special function related to treating, preventing \& diagnosing diseases, sometimes called smart drugs or theragnostics. ${ }^{8}$

The goal of this system:

a. More specific drug targeting \& delivery.

b. Reduction in toxicity while maintaining therapeutic effect.

c. Greater safety \& biocompatibility.

d. Faster development of new \& safe medicines.

This can be achieved by molecular targeting by nanoengineered devices. ${ }^{8,9}$ It is all about targeting the molecules and delivering drugs with cell precision.

Drug delivery systems, lipid- or polymer-based nanoparticles, ${ }^{10}$ can be designed to improve the pharmacological and therapeutic properties of drugs. ${ }^{11}$ The strength of drug delivery systems is their ability to alter the pharmacokinetics and biodistribution of the drug. When designed to avoid the body's defence mechanisms. ${ }^{12}$ nanoparticles have beneficial properties that can be used to improve drug delivery. Where larger particles would have been cleared from the body, cells take up these nanoparticles because of their size. Drugs are placed in the body and only activate on encountering a particular signal. For example, a drug with poor solubility will be replaced by a drug delivery system where both hydrophilic and hydrophobic environments exist, improving the solubility. ${ }^{13}$ Also, a drug may cause tissue damage, but with drug delivery, regulated drug release can eliminate the problem. If a drug is cleared too quickly from the body, this could force a patient to use high doses, but with drug delivery systems clearance can be reduced by altering the pharmacokinetics of the drug. Poor biodistribution is a problem that can affect normal tissues through widespread distribution, but the particulates from drug delivery systems lower the volume of distribution and reduce the effect on non-target tissue. One of the major impacts of nanotechnology and nanoscience will be in leading development of completely new drugs with more useful behavior and less side effects.

Table 1: Overview of nanoparticles and their applications in life sciences.

\begin{tabular}{|c|c|c|}
\hline Particle class & Materials & Application \\
\hline $\begin{array}{l}\text { Natural } \\
\text { materials } \\
\text { or derivatives }\end{array}$ & $\begin{array}{l}\text { Gelatine } \\
\text { Liposomes } \\
\text { Starch }\end{array}$ & $\begin{array}{l}\text { Drug/Gene } \\
\text { delivery }\end{array}$ \\
\hline Dendrimers & $\begin{array}{l}\text { Branched } \\
\text { polymers }\end{array}$ & Drug delivery \\
\hline Fullerenes & $\begin{array}{l}\text { Carbon based } \\
\text { carriers }\end{array}$ & $\begin{array}{l}\text { Photodynamics } \\
\text { Drug delivery }\end{array}$ \\
\hline $\begin{array}{l}\text { Polymer } \\
\text { carriers }\end{array}$ & $\begin{array}{l}\text { Polyethyleinemine } \\
\text { Block copolymers }\end{array}$ & $\begin{array}{l}\text { Drug/gene } \\
\text { delivery }\end{array}$ \\
\hline Ferrofluids & $\begin{array}{l}\text { SPIONS } \\
\text { USPIONS }\end{array}$ & Imaging (MRI) \\
\hline Quantum dots & $\mathrm{Cd} / \mathrm{Zn}$-selenides & $\begin{array}{l}\text { Imaging } \\
\text { In vitro } \\
\text { diagnostics }\end{array}$ \\
\hline Various & $\begin{array}{l}\text { Silica-nanoparticles } \\
\text { Mixtures of above }\end{array}$ & Gene delivery \\
\hline
\end{tabular}

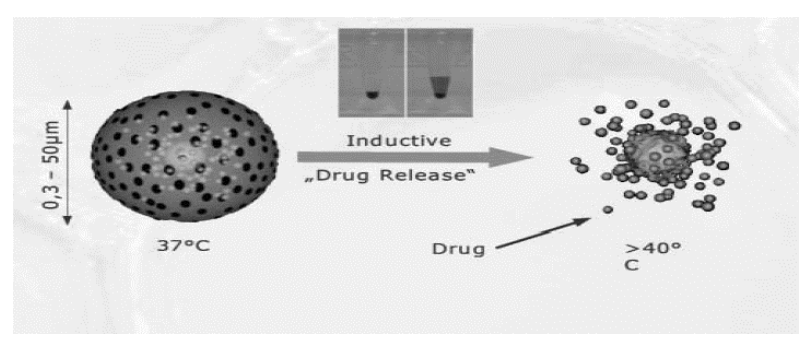

Figure 2: Illustration of contactless controllable drug carrying system based on thermosensitive magnetic nano- \& micro particles. 
The basic point to use drug delivery is based upon three facts:

a) Efficient encapsulation of the drugs,

b) Successful delivery of said drugs to the targeted region of the body

c) Successful release of that drug there.

\section{Nano carriers as Drug Delivery Systems}

$\checkmark \quad$ Exhibit higher intracellular uptake

$\checkmark$ Can penetrate the submucosal layers while the microcarriers are predominantly localized on the epithelial lining.

$\checkmark \quad$ Can be administered into systemic circulation without the problems of particle aggregation or blockage of fine blood capillaries.

$\checkmark$ The development of targeted delivery is firmly built on extensive experience in pharmacochemistry, pharmacology, toxicology, and nowadays is being pursued as a multi-and interdisciplinary effort

"NanoBioPharmaceutics" aims at breakthrough advances in novel biopharmaceutics delivery systems for the treatment of diabetes, cancer, AIDS, Alzheimer's disease, and other neurodegenerative diseases.

\section{B. Protein Detection ${ }^{14}$}

Proteins are the important part of the cell's language, machinery and structure, and understanding their functionalities is extremely important for further progress in human well being. Gold nanoparticles are widely used in immunohistochemistry to identify protein-protein interaction.

\section{Cancer Therapy}

The small size of nanoparticles can be very useful in oncology, particularly in imaging. Quantum dots when used in conjunction with magnetic resonance imaging, can produce exceptional images of tumor sites. ${ }^{15}$ These nanoparticles are much brighter than organic dyes and only need one light source for excitation which shows that the use of fluorescent quantum dots could produce a higher contrast image and at a lower cost than today's organic dyes used as contrast media. But the drawback is quantum dots are usually made up of quite toxic elements.

Another nanoproperty, high surface area to volume ratio, allows many functional groups to be attached to a nanoparticle, which can seek out and bind to certain tumor cells. Additionally, the small size of nanoparticles (10 to 100 nanometers), allows them to preferentially accumulate at tumor sites (because tumors lack an effective lymphatic drainage system).

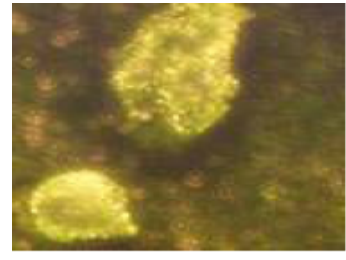

Gold

nanoparticles

stick to cancer

cells and make

them shine

\section{Figure 3: Structure of gold nanoparticle.}

Sensor test chips containing thousands of nanowires, able to detect proteins and other biomarkers left behind by cancer cells, could enable the detection and diagnosis of cancer in the early stages from a few drops of a patient's blood. $^{16}$

The nanoshells can be targeted to bond to cancerous cells by conjugating antibodies or peptides to the nanoshell surface. By irradiating the area of the tumor with an infrared laser, which passes through flesh without heating it, the gold is heated sufficiently to cause death to the cancer cells. $^{17}$

\section{Visualization}

Tracking movement can help determine how well drugs are being distributed or how substances are metabolized. It is difficult to track a small group of cells throughout the body, so scientists used to dye the cells.

The way out of this problem is use of quantum dots, which is a tiny particle or nanoparticles of semiconductor materials (e.g.: selenides or sulfide) of metals in all three spatial dimension. They are more superior to traditional organic dyes. Quantum dots are 20 times brighter \& 100 times more stable than traditional dyes. ${ }^{15}$

\section{E. Drug \& Gene Therapy ${ }^{18,19}$}

Gene therapy can be used to treat different hereditary or acquired diseases. Successful gene therapy depends on two important aspects:

a) Efficient \& safe delivery of genes to the target cells in vitro $\&$ in vivo $\rightarrow$ to achieve this it is necessary to improve transduction efficiency, viral titre when using viral gene therapy or transfection efficiency when using nucleic acids.

b) Effective monitoring of modified cells or modifying agents by non invasive imaging techniques.

To achieve the above two, a new approach is being addressed 'magnetic nanoparticles'. In gene delivery, the nano particles used in MRI present important advantages over other imaging techniques. ${ }^{20-22}$

It has been also reported that the use of nanoparticles to deliver viral vectors (e.g.: adeno, retro) \& nucleic acid is known as magnetofection \& theragnostic. It also aims to 
monitor the response to treatment $\&$ to increase efficacy \& safety. ${ }^{23}$

Current methods have significant limitations, including the risk of inadvertent transmission of disease by viral vectors. This has led researchers to explore polymerDNA complexes and liposome-DNA complexes for gene delivery. ${ }^{24}$ It has also been shown that compacted DNA in the form of nanoparticles can be used to transfect post mitotic cells. ${ }^{25}$

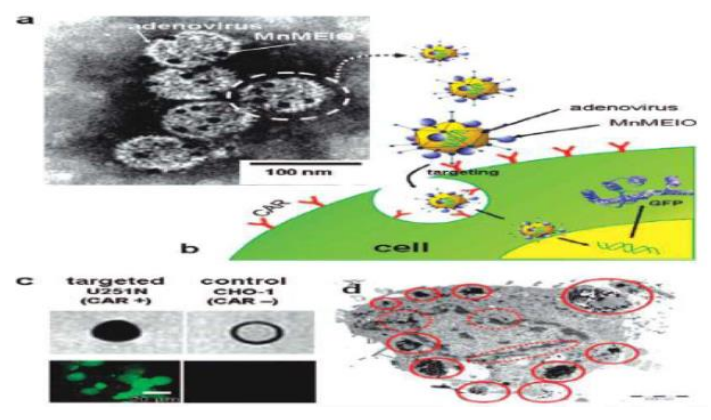

Figure 4: Adenovirus-MnMEIO nanobioconjugates for targeted MRI and gene delivery.

\section{F. Tumour Destruction Via Heating (Hyperthermia) ${ }^{26}$}

Magnetite cationic liposomes (MCLs), which are cationic liposomes containing 10-nm magnetite nanoparticles, in order to improve the accumulation of magnetite nanoparticles in target cells using the electrostatic interaction between MCLs and the cell membrane. ${ }^{27}$ Hyperthermia is one of the promising approaches in cancer therapy, and various methods have been employed in hyperthermia. ${ }^{28,29}$ The most commonly used heating method in clinical settings is capacitive heating using a radiofrequency (RF) electric field. ${ }^{30}$ MCLs were developed for intracellular hyperthermia $^{27,31,32}$, which showed a ten-fold higher affinity for the tumor cells than neutrally charged magnetoliposomes. ${ }^{31}$ Based on this feature, MCLs can be highly superior heating mediators.

\section{G. Phagokinetic Studies ${ }^{33}$}

The uptake of colloidal semiconductor nanocrystals by a large range of eukaryotes is directly correlated with the cell motility, as has been shown by comparing the motions of cancerous and healthy human breast cells. The nanocrystals are more photochemically robust than organic dyes and provide a powerful tool for studying the processes of cell motility and migration.

\section{H. Tissue Engineering ${ }^{34,35}$}

Natural bone surface is quite often contains features that are about $100 \mathrm{~nm}$ across thickness. If the surface of an artificial bone implant were left smooth, the body would try to reject it. Because of that smooth surface is likely to cause production of a fibrous tissue covering the surface of the implant. This layer reduces the bone-implant contact, which may result in loosening of the implant and further inflammation. It was demonstrated that by creating nano-sized features on the surface of the hip or knee prosthesis one could reduce the chances of rejection as well as to stimulate the production of osteoblasts.

More than $90 \%$ of the human bone cells from suspension adhered to the nanostructured metal surface, ${ }^{36}$ but only $50 \%$ in the control sample. It was shown that using a biomimetic approach - a slow growth of nanostructured apatite film from the simulated body fluid - resulted in the formation of a strongly adherent, uniform nanoporous layer. $^{34}$

\section{MRI Contrast Enhancement ${ }^{37}$}

An ultrasmall superparamagnetic iron oxide (USPIO) preparation was developed that is small enough to migrate across the capillary wall, a prerequisite in the design of targetable particulate pharmaceuticals. Seventy percent of particles were smaller than $10 \mathrm{~nm} ; 26 \%$, smaller than $5 \mathrm{~nm}$. The blood half-life of USPIO in rats was 81 minutes, considerably longer than that of larger superparamagnetic iron oxide preparations such as AMI25 (6 minutes). The major potential applications for USPIO are as (a) an intravenous contrast agent for the lymphatic system, (b) a bone marrow contrast agent, (c) a long-half-life perfusion agent for brain and heart, and (d) the magnetic moiety in organ-targeted superparamagnetic contrast agents for magnetic resonance imaging.

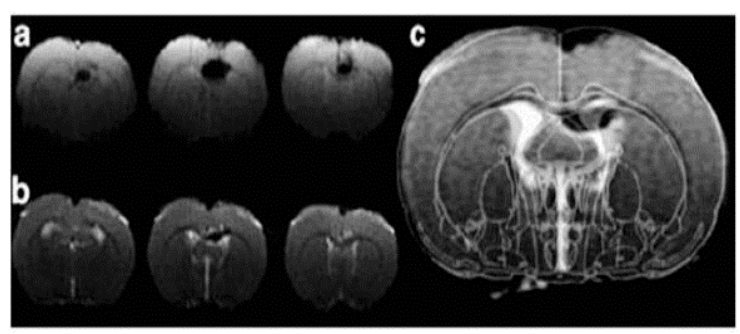

Figure 5: MRI of intraventricular biotinilated USPIO1 Baavi delivery.

\section{J. DNA Probe ${ }^{38}$}

Nucleic acid molecules can serve as robust ligands for aqueous synthesis of semiconductor nanocrystals or quantum dots (QDs). These nanomaterials are photoluminescent and being developed both as dyes \& as sensors. Structural polymorphism in DNA may serve as a biological signal in vivo, highlighting the need for recognition of DNA structure in addition to DNA sequence in biotechnology assays.

\section{K. Fluorescent Biological Labels ${ }^{39}$}

The colloidal nanocrystals can be used as fluorescent labels for biological tagging experiments. Biological 
tagging is one of the most widely employed techniques for diagnostics and visualization.

\section{Separation and Purification of Biological Molecules \& Cells $^{40}$}

Ferromagnetic iron dextran particles were prepared by reacting a mixture of ferrous chloride and ferric chloride with dextran polymers under alkaline conditions. Protein A from Staphylococcus aureus was covalently coupled to periodate-oxidized ferromagnetic iron-dextran particles. These conjugates were used to indirectly label antigen sites on human red blood cells and thymocytes for visualization by scanning and transmission electron microscopy. They are used in the separation of cells, cell membranes and receptors and in drug targeting studies.

\section{ADVANTAGES OF NANOTECHNOLOGY}

In the medical world, nanotechnology is also seen as a boon since these can help with creating what is called smart drugs.

- These help cure people faster and without the side effects that other traditional drugs have.

- The research of nanotechnology in medicine is now focusing on areas like tissue regeneration, bone repair, immunity and even cures for such ailments like cancer, diabetes and other life threatening diseases.

\section{DISADVANTAGES OF NANOTECHNOLOGY}

- Since these particles are very small, problems can actually arise from the inhalation of these minute particles, much like the problems a person gets from inhaling minute asbestos particles.

- Presently, nanotechnology is very expensive and developing it can cost a lot of money. It is also pretty difficult to manufacture, which is probably why products made with nanotechnology are more expensive.

- Nanomaterials are developed for their unique (surface) properties in comparison to bulk materials. When nanoparticles are used for their unique reactive characteristics it may be expected that these same characteristics also have an impact on the toxicity of such particles. This may differ depending on the type of particles used, ie, biological versus nonbiological origin.

- Nanoparticles are attributed qualitatively different physico-chemical characteristics from micron-sized particles, which may result in changed body distribution, passage of the blood brain barrier, and triggering of blood coagulation pathways.

- Effects of combustion derived nanoparticles in environmentally exposed populations mainly occur in diseased individuals. Typical preclinical screening is almost always done in healthy animals and volunteers and risks of particles may therefore be detected at a very late stage.

\section{SUMMARY}

Applications of nanotechnology for treatment, diagnosis, monitoring, and control of biological systems has recently been referred to as "nanomedicine" by the National Institutes of Health. Research into the rational delivery and targeting of pharmaceutical, therapeutic, and diagnostic agents is at the forefront of projects in nanomedicine. These involve the identification of precise targets (cells and receptors) related to specific clinical conditions and choice of the appropriate nanocarriers to achieve the required responses while minimizing the side effects. Mononuclear phagocytes, dendritic cells, endothelial cells, and cancers (tumor cells, as well as tumor neovasculature) are key targets. Today, nanotechnology and nanoscience approaches to particle design and formulation are beginning to expand the market for many drugs and are forming the basis for a highly profitable niche within the industry, but some predicted benefits are hyped. In the future, a world where medical nanodevices are routinely implanted or even injected into the bloodstream to monitor wellness and to automatically participate in the repair of systems that deviate from established norms could be imagined. These nanobots could be personalized by tailoring them to patient genotype and phenotype to optimize intervention at the earliest stage in the course of disease expression.

\section{REFERENCES}

1. Nanotechnology in Medicine: Huge Potential, But What Are The Risks? Available at http://www.medicalnewstoday.com/articles/244972. php. Accessed 4 January 2013

2. Sinani VA, Koktysh DS, Yun BG, Matts RL, Pappas TC, Motamedi M, Thomas SN, Kotov NA. Collagen coating promotes biocompatibility of semiconductor nanoparticles in stratified LBL films. Nano Letters 2003, 3:1177-82.

3. Zhang Y, Kohler N, Zhang M. Surface modification of superparamagnetic magnetite nanoparticles and their intracellular uptake. Biomaterials 2002, 23:1553-61.

4. Boisseau, P, Loubaton, B, "Nanomedicine, nanotechnology in medicine". Comptes Rendus Physique .2011;12 (7):620.

5. Nanospectra Biosciences, Inc. - Publications http://www.nanospectra.com/clinicians/spublication s.html.

6. Mozafari, M.R.(ed), Nanocarrier Technologies: Frontiers of Nanotherapy. 2006;(Chapters 1 and 2):10-11, 25-34. 
7. Bertrand N, Bouvet C, Moreau P and Leroux JC. "Transmembrane pH-Gradient Liposomes To Treat Cardiovascular Drug Intoxication". ACS Nano 2010;4(12):7552-8.

8. La Van DA, Mc Guire T, Langer R. Small scale systems for in vivo drug delivery. Nat Biotechnol 2003; 21:1184-91

9. Cavalcanti A, Shirinzadeh B, Freitas RA Jr, Hogg T. "Nanorobot architecture for medical target identification". Nanotechnology 2008;19(1): 015103(15pp).

10. University of Waterloo, Nanotechnology in Targeted Cancer Therapy, 15 January 2010.

11. Allen TM, Cullis PR. "Drug Delivery Systems: Entering the Mainstream". Science. 2004;303 (5665):1818-22.

12. Bertrand N, Leroux JC. "The journey of a drug carrier in the body: an anatomo-physiological perspective". Journal of Controlled Release. (2011).

13. Nagy ZK, Zsombor K.; Balogh A, Vajna B, Farkas A, Patyi G, Kramarics A, Marosi G. "Comparison of Electrospun and Extruded Soluplus-Based Solid Dosage Forms of Improved Dissolution". Journal of Pharmaceutical Sciences: (2011).

14. Cao YC, Jin R, Nam JM, Thaxton CS, Mirkin CA. Raman dyelabeled nanoparticle probes for proteins. JACS 2003, 125:14676-7.

15. Walling MA, Novak, sephard. Quantu Dots for live cell \& in vivo imaging. Int J Mol Sci. 2009;10(2): 441-91.

16. Zheng G, Patolsky F, Cui Y, Wang WU, Lieber CM. "Multiplexed electrical detection of cancer markers with nanowire sensor arrays". Nat Biotechnol 2005;23(10):1294-1301.

17. Loo C, Lin A, Hirsch L, Lee MH, Barton J, Halas N, West J, Drezek R. "Nanoshell-enabled photonicsbased imaging and therapy of cancer". Technol Cancer Res Treat 2004;3(1):33-40.

18. Mah C, Zolotukhin I, Fraites TJ, Dobson J, Batich C, Byrne BJ. Microsphere-mediated delivery of recombinant AAV vectors in vitro and in vivo. Mol Therapy 2000,1:S239.

19. Panatarotto D, Prtidos CD, Hoebeke J, Brown F, Kramer E, Briand JP, Muller S, Prato M, Bianco A. Immunization with peptide-functionalized carbon nanotubes enhances virus-specific neutralizing antibody responses. Chemistry \& Biology 2003;10:961-6.

20. Doshi N, Mitragotri S. Designer biomaterials for nano medicine. Adv Funct Mater 2009;19:3843-54.

21. Gould P. Nano particles probe biosystem. Mater Today. 2004; 7: 36-43.

22. Portney NG et al. Organic \& inorganic nanoparticles hybrid. Langmuir: Acs J Surf Colloids.2005; 21: 2098-2103.

23. Fernando $\mathrm{H}$ etal. The application of nanoparticles in genetherapy \& MRI. Microsc. Res Tech.2011; 74(7):577-591.

24. Xu L., Frederik P. and Pirollo K.F., "Self-Assembly of A Virus-Mimicking Nanostructure System for
Efficient Tumour-Targeted Gene Delivery", Hum. Gene Ther. 2002;13: 469-481.

25. Liu G., Li D., Pasumarthy M.K., et al., "Nanoparticles of Compacted DNA Transfect Postmitotic Cells". J Biol Chem 2003;278:3257832586.

26. Yoshida J, Kobayashi T. Intracellular hyperthermia for cancer using magnetite cationic liposomes. J Magn Magn Mater 1999;194:176-84.

27. Shinkai M, Yanase M, Honda H, Wakabayashi T, Yoshida J, Kobayashi T. Intracellular hyperthermia for cancer using magnetite cationic liposomes: in vitro study. Jpn J Cancer Res 1996;87:1179-83.

28. Stauffer PR, Cetas TC, Jones RC: System for producing localized hyperthermia in tumors through magnetic induction heating of ferromagnetic implants. Natl Cancer Inst Monogr 1982;61:483487.

29. Brezovich IA, Atkinson WJ, Lilly MB: Local hyperthermia with interstitial techniques. Cancer Res .1984;44(Suppl 10):4752s-4756s.

30. Ikeda N, Hayashida O, Kameda H, Ito H, Matsuda T: Experimental study on thermal damage to dog normal brain. Int J Hyperthermia 1994, 10:553-561.

31. Yanase M, Shinkai M, Honda H, Wakabayashi T, Yoshida J, Kobayashi T: Intracellular hyperthermia for cancer using magnetite cationic liposomes: ex vivo study. Jpn J Cancer Res 1997; 88:630-632.

32. Yanase M, Shinkai M, Honda H, Wakabayashi T, Yoshida J, Kobayashi T: Intracellular hyperthermia for cancer using magnetite cationic liposomes: an in vivo study. Jpn J Cancer Res 1998; 89:463-469.

33. Parak WJ, Boudreau R, Gros ML, Gerion D, Zanchet D, Micheel CM, Williams SC, Alivisatos AP, Larabell CA: Cell motility and metastatic potential studies based on quantum dot imaging of phagokinetic tracks. Adv Mater 2002; 14:882-885.

34. Ma J, Wong H, Kong LB, Peng KW: Biomimetic processing of nanocrystallite bioactive apatite coating on titanium. Nanotechnology 2003; 14:619. 623.

35. de la Isla A, Brostow W, Bujard B, Estevez M, Rodriguez JR, Vargas S, Castano VM: Nanohybrid scratch resistant coating for teeth and bone viscoelasticity manifested in tribology. Mat Resr Innovat 2003; 7:110-114.

36. Gutwein LG, Webster TJ. Affects of alumina and titania nanoparticulates on bone cell function. American Ceramic Society 26th Annual Meeting Conference Proceedings 2003, in press.

37. Roy I, Ohulchanskyy TY, Pudavar HE, Bergey EJ, Oseroff AR, Morgan J, Dougherty TJ, Prasad PN: Ceramic-based nanoparticles entrapping waterinsoluble photosensitizing anticancer drugs: a novel drug-carrier system for photodynamic therapy. J Am Chem Soc 2003; 125:7860-7865.

38. Mahtab R, Rogers JP, Murphy CJ: Protein-sized quantum dot luminescence can distinguish between "straight", "bent", and "kinked" oligonucleotides. J Am Chem Soc 1995; 117:9099-9100. 
39. Chan WCW, Nie SM. Quantum dot bioconjugates for ultrasensitive nonisotopic detection. Science 1998; 281:2016-8.

40. Molday RS, MacKenzie D. Immunospecific ferromagnetic iron dextran reagents for the labeling and magnetic separation of cells. J Immunol Methods 1982;52:353-67.

doi:10.5455/2319-2003.ijbcp20130802

Cite this article as: Jena M, Mishra S, Jena S, Mishra SS. Nanotechnology- future prospect in recent medicine: a review. Int J Basic Clin Pharmacol 2013;2:353-9. 